\title{
ABSORPTION STUDIES USING PORTAL ANASTOMOTIC VEINS ${ }^{1}$

\author{
By WILLIAM BENNETT BEAN, MURRAY FRANKLIN, JAMES F. EMBICK, AND \\ KATE DAUM
}

\author{
(From the Department of Internal Medicine of the College of Medicine, State University of \\ Iowa and the University Hospitals, Iowa City)
}

(Submitted October 13, 1950; accepted, December 11, 1950)

In man the portal circulation, being without major and macroscopic connection with systemic veins, has been hidden from the clinical investigator. Even the intravascular catheter has not invaded the duplex circulations feeding the liver, but only its drainage system. Thus circulatory inaccessability of the key digestive gland in man has left it mysterious, a metabolic sphinx. Surgeons, deleting the spleen from persons with portal hypertension, have recorded sporadic data on portal pressure and blood gases $(1,2)$. 'Physiologists have estimated total hepatic blood flow in man by the bromsulphalein clearance test (3) which permits at least reasonable approximations. Sherlock and Walshe (4) added some facts by measuring portal blood from large superficial anastomotic veins in a single patient with cirrhosis. They reported observations in a patient with a large abdominal vein apparently draining blood from the upper segment of the alimentary canal into the right great saphenous vein. Their attention was concentrated on a comparison of systemic and anastomotic blood levels of glucose, galactose, fructose, fat and nitrogen at appropriate intervals after ingestion of measured quantities of these substances or their precursors, singly or in combination.

The ordinary collateral veins over the abdomen of cirrhotic patients have been studied in an effort to determine portal pressures $(1,5)$ and circulation time (6). Billings and DePree suggested that comparison of blood from the abdominal collaterals and systemic veins following administration of glucose orally might permit the differentiation of cirrhosis from other disorders giving rise to collateral vessels over the belly (7).

\footnotetext{
1 Aided in part by the Medical Trust Fund of the Department of Internal Medicine, and research grants from the Division of Research Grants and Fellowships of the National Institutes of Health, U. S. Public Health Service, and the Commission on Liver Disease of the Armed Forces Epidemiological Board.
}

Myers (8) has made an effort at physiologic partition of hepatic arterial and portal venous components of the total blood flow to the liver by measuring the gas content of arterial, hepatic vein and caput medusae blood. If one assumes that there has been no reflux from hepatic artery into the portal anastomotic vessel and that the cases were not indeed instances of the CruveilhierBaumgarten syndrome (9), such observations may bring crucial evidence to impinge on Dock's surprising observations on postmortem infusion of hepatic artery and portal vein with kerosene (10).

We are reporting studies on two patients (see Appendix) with cirrhosis who had portal anastomotic veins large enough to permit multiple studies of absorption. One of these patients died and postmortem examination revealed an unusual connection between a branch of the superior mesenteric vein and the superficial abdominal vein which coursed upward and emptied into the superior vena cava via the left internal mammary and innominate veins. Details of the connections are given in Figures 9 and 10. Our observations were restricted in part by the chemical facilities at hand when the two patients were under observation almost simultaneously on the wards. By the time we had prepared to do more elaborate tests, one patient died in the hospital and the other went home and died. No others with such vessels have been found in our last 20 cirrhotic patients. Therefore, we are presenting our data as modest increments to knowledge which must be extended before we draw general conclusions.

\section{METHODS}

Our observations were made by comparing the levels of constituents of blood samples taken simultaneously from the antecubital and portal anastomotic vein at appropriate intervals after the ingestion of the mixture whose composition is listed in Table I. Studies included those on glucose (11), fructose (12) and vitamin A (13, 


\author{
TABLE I \\ Contents of test meal \\ 60 grams of protein (skim milk and \\ skim milk powder) \\ 80 grams of fat (cream) \\ 50 grams of glucose \\ 50 grams of fructose \\ $500 \mathrm{mg}$. of ascorbic acid \\ $5 \mathrm{mg}$. of thiamine \\ 10,000 units vitamin A (M. W.) \\ 25,000 units vitamin A (N. N.) \\ $250 \mathrm{ml}$. water
}

$14)$, neutral fat (15), thiamine $(16,17)$, ascorbic acid (18), amino acid nitrogen (19) and urea nitrogen by the urease method. In no case was the error of the method more than $\pm 5 \%$. We did all tests in duplicate except for glucose and urea nitrogen. The amount of blood which could be withdrawn from the abdominal vein sometimes limited the number of tests it was possible to do. Some samples were used for tests which would have been omitted had we been able to predict results. We collected further data on oxygen saturation before and after eating; on circulation time and venous pressure. We did the absorption studies the day following paracentesis in order to reduce by some degree the mechanical interference with alimentary function and to make the abdominal vein more accessible. For a period of one week prior to each absorption study, both patients were fed a high-carbohydrate, high-protein and unrestricted-fat diet. Supplemental vitamins were furnished in the form of multi-vitamin capsules and crude brewer's yeast. In addition, subject $M$. W. received thiamine, riboflavin and vitamin $\mathrm{K}$.

\section{OBSERVATIONS}

The information collected in this study is presented in a series of charts.

\section{Carbohydrate}

Blood samples were taken after a 14-hour fast, and 50 grams of glucose were given orally at zero time. From Figure 1 the following facts are noted.

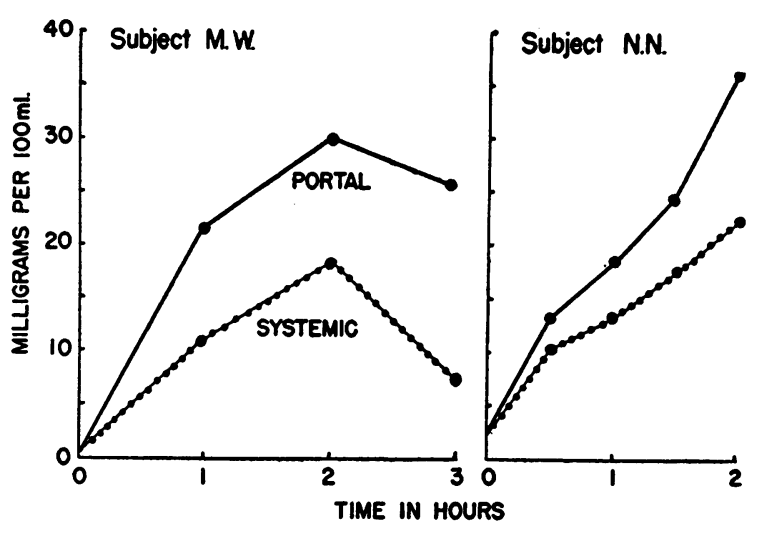

Fig. 2. Comparison of Portal and Systemic Blood Fructose Levels following Ingestion of Test Meal

(1) The fasting level of glucose in abdominal and antecubital vein was the same. (2) In all tests the level of glucose rose more rapidly, and for $11 / 2$ to two hours was sustained consistently at higher levels in the abdominal vein than in the vein of the arm. In the first test in subject $M$. W. the level of glucose in the abdominal vein and arm vein was elevated above the normal at the two-hour period. In the second test the abdominal vein blood showed higher glucose values at the end of two hours with the levels both approaching normal at the end of three hours. The third test three months later when the patient was clinically much worse showed a high glucose level in the abdominal vein blood at the end of two hours. No later determinations were made. (3) In subject N. N. the arm and abdominal blood glucose levels were slightly elevated with the abdominal blood level being higher at the end of two hours. There was no regularity of time relations for peak of glucose

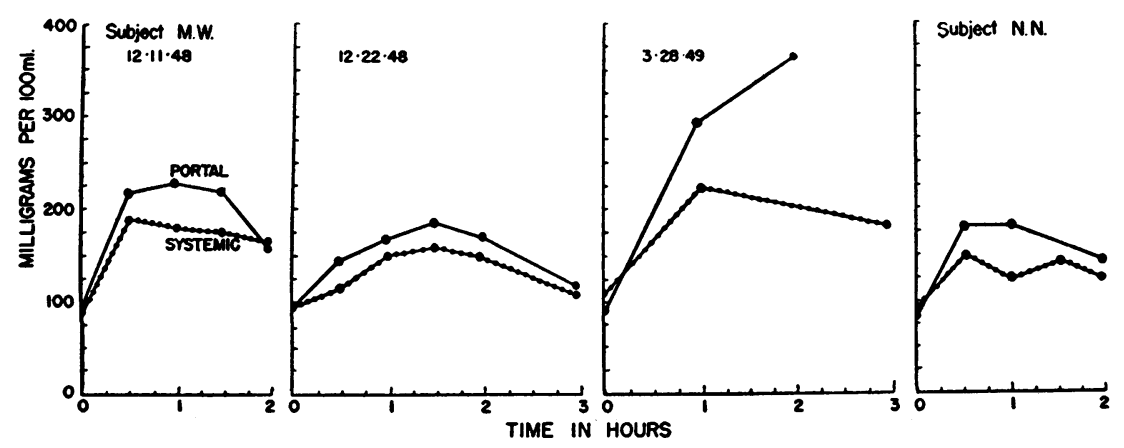

Fig. 1. Comparison of Portal and Systemic Blood Glucose Levels following Ingestion of Test Meal 
in the abdominal vein, although the average time for peak elevation was somewhat later (75 min.) than for the arm vein ( $53 \mathrm{~min}$.). The peaks in all four tests differed varying from one-half to two hours. The fasting blood glucose levels were normal in both subjects. (4) Fructose (Figure 2)-Both subjects had normal fasting levels and a decreased tolerance. The absolute value of the blood fructose was less than that of glucose although proportionately the rise of fructose was greater than that of glucose. Except for the fasting samples, the fructose levels in the abdominal vein were higher at all times in both subjects. Peak level in abdominal and arm vein blood occurred at the end of two hours. No later determinations were carried out on subject N. N.

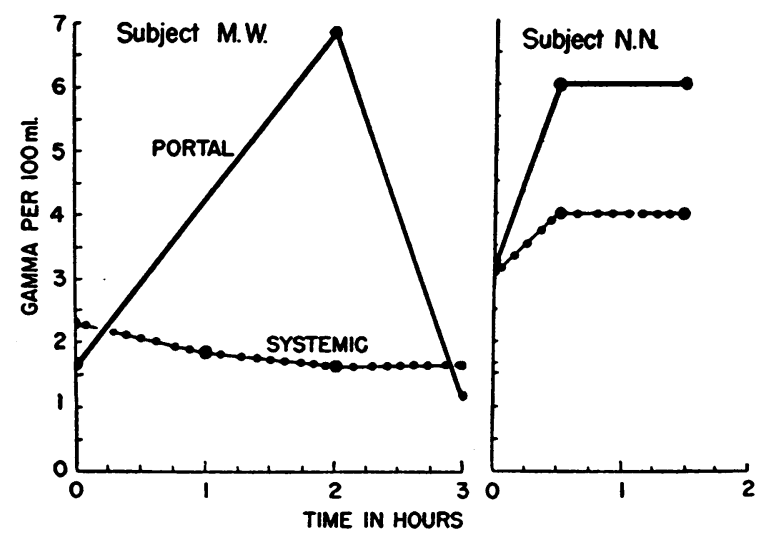

Fig. 3. Comparison of Portal and Systemic Blood Thiamine Levels following Ingestion of Test Meal

\section{Water Soluble Vitamins}

Five mg. of thiamine were given orally as the test dose. There was no clinical clue to specific thiamine deficit but the dietary history suggested that there was moderate thiamine undernutrition.

From Figure 3 it may be seen that: (1) Anastomotic vein blood rose to much higher levels than did blood from the arm vein. (2) Rise in systemic vein was absent or very slight. (3) The curves do not have enough points to describe a general pattern of behavior. (4) In one subject the thiamine level of anastomotic vein blood had returned to the control level at three hours.

Ascorbic acid was given orally in the amount of $500 \mathrm{mg}$. Figure 4 reveals that: (1) There was no substantial difference in the levels from portal and systemic blood in fasting or postprandial sam-

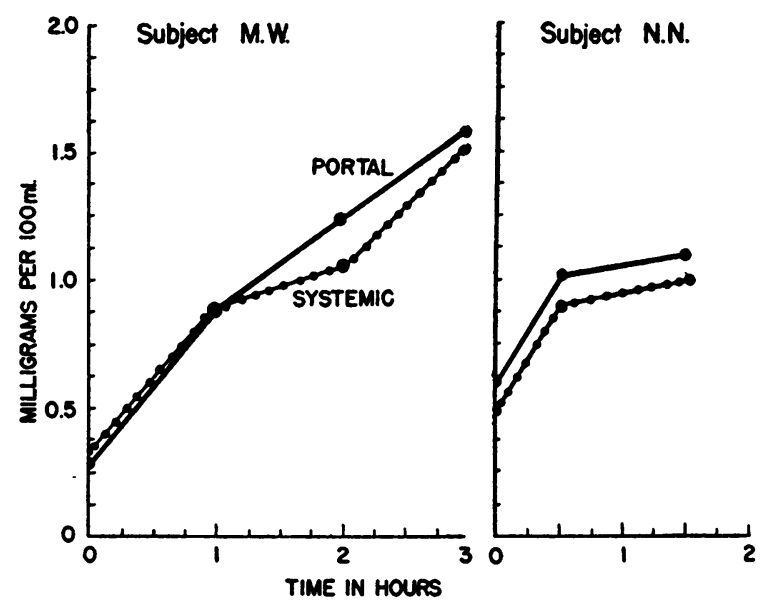

Frg. 4. Comparison of Portal and Systemic Blood Ascorbic Acid Levels following Ingestion of Test Meal

ples. (2) Portal blood was regularly higher than systemic blood, though not to a significant degree. (3) No fall in level had occurred at the end of two or three hours in the two cases.

\section{Vitamin $A$}

Vitamin A was given orally, 10,000 units, to subject $M$. W. and 25,000 units to subject $N$. N. Figure 5 reveals: (1) Similar fasting levels in portal and systemic blood. (2) More rapid and higher rises in portal than in systemic blood. (3) Return to control values at three hours in one subject.

\section{Neutral Fat}

Neutral fat was given as 80 grams of cream. Figure 6 indicates: (1) A distinctly higher systemic than portal fasting level. (2) Irregular

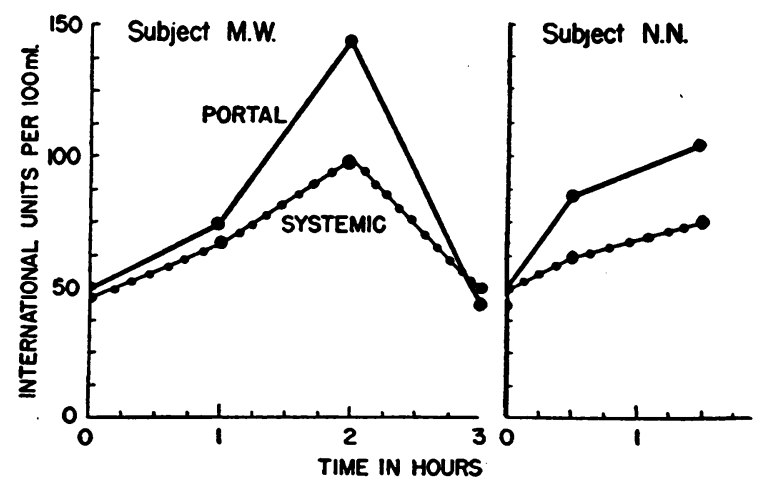

Fig. 5. Comparison of Portal and Systemic Blood Vitamin A Levels following Ingestion of Test Meal 


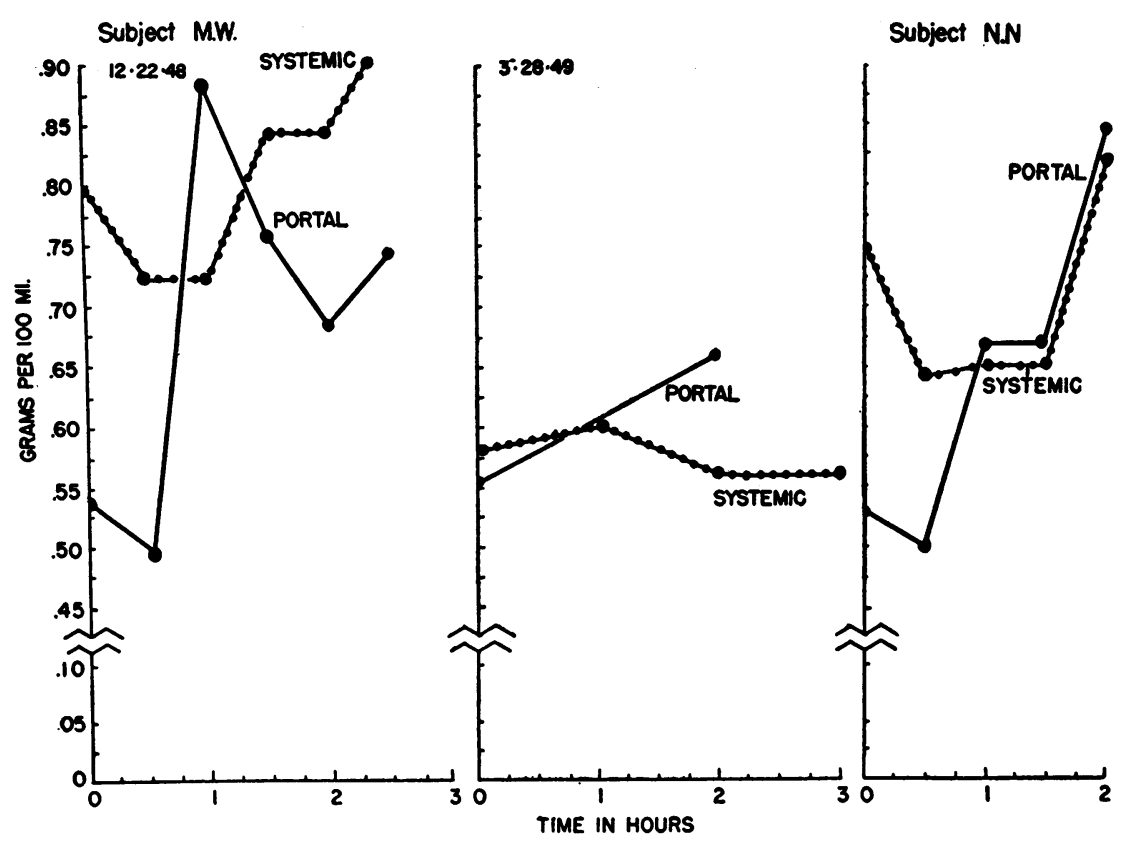

Fig. 6. Comparison of Portal and Systemic Blood Plasma Lipid Levels following Ingestion of Test Meal

rises in which portal blood levels rose at a more rapid rate. (3) Two of the three tests indicate a delayed rise of lipid in systemic blood.

\section{Nitrogen}

Sixty grams of protein in the form of skim milk and skim milk powder were given. Figure 7 for amino acid nitrogen indicates that: (1) The tests showed no clear difference in portal and anastomotic vein levels of amino acid nitrogen though there was a tendency for a peak to occur at two to $2 \frac{1}{2}$ hours. (2) The levels varied erratically.

Figure 8, indicating blood urea nitrogen, shows : (1) Similar fasting levels in portal and systemic blood; (2) a rise in systemic blood urea nitrogen at one hour, in one instance falling rapidly and in the other sustained for some time.

\section{Circulation Time}

Circulation time was determined by the decholin method. The results are in Table II. The

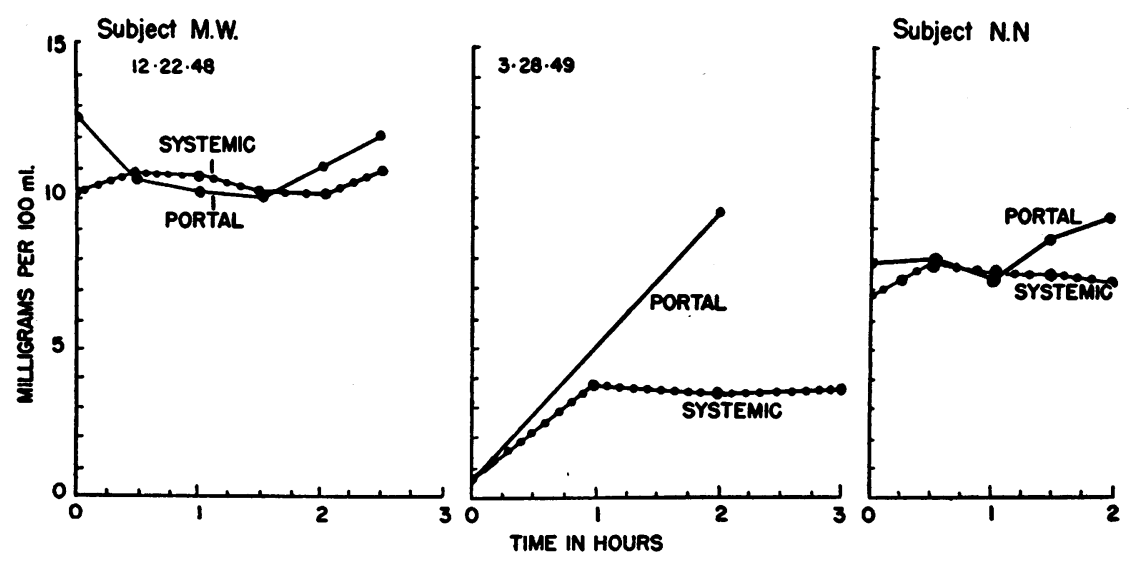

Fig. 7. Comparison of Portal and Systemic Blood Amino Acid Levels following Ingestion of Test Meal 
blood from the abdominal vein reached the tongue in 11 and 14 seconds, distinctly less than the arm to tongue time. Femoral vein to tongue time was at the upper range of normal.

\section{Venous Pressure}

The determinations of portal vein pressure are compared with those from the antecubital and femoral vein in Table III. The right atrium was the standard zero reference.

In one subject (N. N.) studies of blood gases were attempted in the fasting state and during absorption. The necessity of producing stasis in order to obtain blood from the portal vein, which

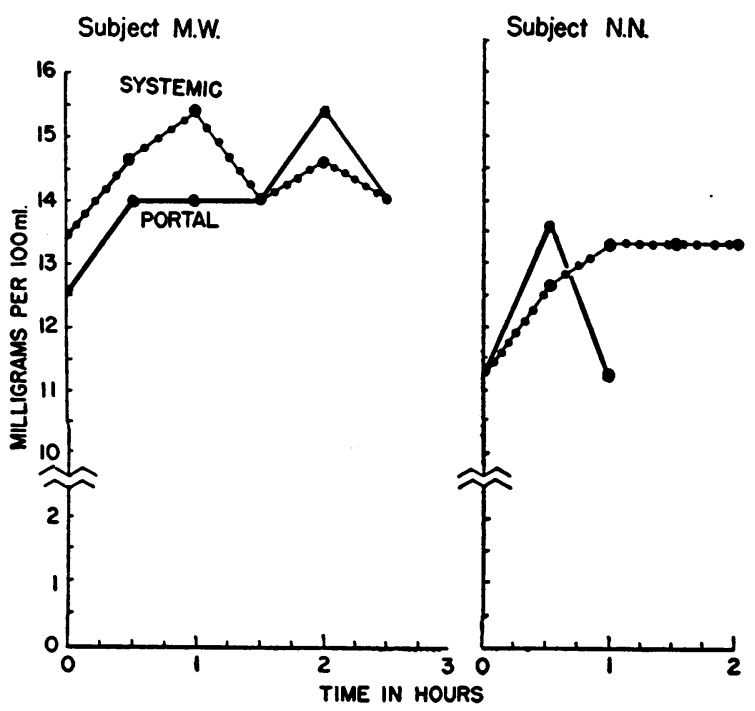

Fig. 8. Comparison of Portal and Systemic Blood Urea Nitrogen Levels following Ingestion of Test Meal

was copied as far as possible in taking blood from the arm, makes the data presented in Table IV of questionable accuracy. The blood from the portal anastomotic vein was regularly of a brighter red color than that from the arm vein.

\section{DISCUSSION}

Although studies of absorption were made by analysis of portal vein blood in animals (20) in 1877 no similar efforts to evaluate the phenomena of absorption in man have been made until recently. While the results of the biochemical tests on various substances are roughly comparable in the two subjects, and postmortem observations
TABLE II

Circulation time in seconds (decholin)

\begin{tabular}{l|c|c}
\hline \hline & M. W. & N. N. \\
\hline Anastomotic vein to tongue & $11^{*}$ & 14 \\
Arm to tongue & 16 & 17 \\
Femoral vein to tongue & 26 & 27 \\
\hline
\end{tabular}

* Each number is the average of two determinations.

in one of them established the anatomical relations of the portal anastomotic vein, the data are scarcely adequate for broad generalization. Together with the patient reported by Sherlock and Walshe (4) whose anastomotic vein carried blood down to the saphenous vein, three subjects with large portal anastomotic veins have been investi-

TABLE III

Venous pressures (cm. water) referred to right atrium as zero point

\begin{tabular}{l|l|c}
\hline \hline & M. W. & N. N. \\
\cline { 2 - 3 } Arm & $11^{*}$ & 9 \\
Arm (after R.U.Q. pressure) & 12.5 & 9 \\
Femoral & 11.5 & 9 \\
Femoral (after R.U.Q. pressure) & 19 & 13 \\
Anastomotic vein & 22 & 19 \\
Anastomotic vein (after R.U.Q. pressure) & 23 & 19 \\
$\begin{array}{l}\text { Anastomotic vein (after Valsalva proce- } \\
\text { dure) }\end{array}$ & 26 & 25 \\
\hline
\end{tabular}

* Each number is the average of two determinations.

gated. Our patients both had a similar pattern of superficial venous drainage in a cephalic direction by a large anastomotic vein. This was demonstrated by local pressure which indicated that the vein filled more rapidly from below than from above; and the exaggerated prominence produced by the Valsalva procedure. Because we

TABLE IV

Oxygen saturation (subject $N . N$.)

\begin{tabular}{l|r|c}
\hline \hline \multicolumn{3}{c}{ Fasting Blood } \\
& Volumes \% & Saturation (\%) \\
\hline & 7.0 & 38.8 \\
Arm vein & 14.0 & 82.5 \\
Anastomotic vein & & \\
\hline \multicolumn{2}{|c|}{ After Meal } \\
\hline Arm vein & 5.0 & 27.8 \\
Anastomotic vein & 14.2 & 79.0 \\
\hline Oxygen capacity & \multicolumn{2}{|c}{18.0} \\
\hline
\end{tabular}


could not estimate the moiety of portal blood carried in this vein, it is idle to speculate upon the quantitative aspects of the data. They merely indicate trends. Another limitation in the study is the reliability of the venous blood from the arm, representing not mixed venous blood but a particular sample. In essence we are comparing the constituents of two different effluent streams of blood, but we cannot relate the observed data to total quantities. The effect of the water of the test feeding added another variable.

A number of factors militate against the application of our findings to the normal processes of absorption in man. The metabolic function of the cirrhotic liver is impaired, but no single test or clinical finding permits precise quantitation of the several disturbances which would influence absorption and hepatic metabolism. The higher pressure of blood in the portal circuit well known clinically, demonstrated at operation $(1,21)$ and measured directly in our subjects might be expected to diminish or retard absorption from the gut. It is not known to what extent commingling of arterial blood from the hepatic artery with venous blood from the intestine occurs, or even that it has any quantitative significance. Our observations, therefore, though they provoke speculation, provide no conclusive solution to the problems they bear upon. Because of the anatomical relations in subject M. W., it is probable that significant admixture with systemic blood did not occur.

Carbohydrate. It is the consensus of investigators that glucose is absorbed by a phosphorylation mechanism with hexose phosphoric acid serving to transport glucose across the mucosa where glucose again is formed and transported as such to the liver. Our studies (Figure 1) suggest that this process is protracted over periods of at least two hours. In all observations the curves of the systemic glucose and fructose blood levels are typical of those found in liver disease, namely, normal fasting levels with decreased tolerance after ingestion of the sugar. The elevated levels are attributed to impairment of the liver's function in carbohydrate regulation. The prolonged elevation likewise may result from hepatic malfunction and probably impaired intestinal absorption as well. The earlier and higher rise and the more rapid return to normal of glucose in contrast to fructose is in keeping with the fact that gastro-intestinal absorption of glucose is more rapid than that of fructose although the rates of utilization in the liver are similar (22). The factors of tissue utilization of glucose, possible glucogenesis from the protein in the test feeding, and the effect of fat in delaying absorption could not be appraised.

Water soluble vitamins. Thiamine levels in portal blood rose rapidly whereas the rise in systemic blood was meagre or did not follow (Figure 3 ). Perhaps this merely reflects thiamine depletion in the tissues. We have no knowledge of what metabolic alterations were produced because of the bypass of so much portal blood to the general systemic circulation before passage through the liver. The fact that portal blood levels rose without a similar rise of systemic blood thiamine raises a question about the usual interpretation of such flat tolerance curves as indicative of reduced absorption; and it must be concluded that thiamine was utilized, stored, destroyed, or excreted rapidly.

Ascorbic acid levels followed a different course; and there was no substantial difference between portal and systemic blood samples. One could interpret this as an indication of a state of saturation, though the initial levels are below the usually accepted normal range. Another assumption might be that the use or elimination of ascorbic acid was diminished.

Fat soluble vitamins. To some extent the curves of vitamin A levels (Figure 5) were similar to those for glucose. Subject N. N., who received 25,000 units, had less of a rise than subject $M$. W., who received 10,000 units though the time intervals of sampling and the duration of the tests differed.

Lipids. There was a sharp disparity between portal and systemic blood levels for neutral fat in the fasting state, suggesting that the liver was liberating fat into the blood stream, or possibly that it was removed somewhere in the long circuit between hepatic vein and the portal collecting system. In two instances there was an initial fall and then a sharp rise in portal blood to levels somewhat higher than the simultaneous systemic blood level.

Nitrogen. Figures 7 and 8 exhibit data from studies on portal and systemic blood urea nitrogen and amino acid nitrogen. Similar levels for amino acid nitrogen occurred during the early stages of 
absorption and not until the second hour was the level in portal blood significantly higher than in systemic vein blood at a time when the breakdown of protein to amino acids in the gut was well advanced. The curves for urea nitrogen (Figure 8) suggest several interpretations. In M. W. it may be supposed that the formation of urea from amino acid was advancing rapidly and reached an early peak, after which the process declined or excretion increased. In N. N. the curves may be taken to suggest the absorption of urea, or its formation in the gut, though the differences are not striking, and the variations suggest that the results may be in error.

Oxygen. It is probable that technical difficulties with the collection of blood from the anastomotic vein, the necessity for using pressure and stasis and efforts to duplicate the situation in the vein of the arm make the quantities unreliable. Nevertheless, in each sample taken from the abdominal vein it was obvious that the blood had the bright red color nearly that of arterial blood. By ordinary inspection, and by the use of red goggles, the anastomotic vein appeared less dark than neighboring veins coursing up over the abdomen. It failed to show up as well as we expected with infrared photography. We have demonstrated in some other patients with cirrhosis identical blood glucose levels in arm and abdominal collateral veins after a test meal, and in spite of the report of Billings and DePree (7), we are of the opinion that some of the prominent abdominal veins in cirrhotics carry unmixed systemic blood from the lower extremity. The high oxygen content of the anastomotic vein may indicate (1) a reflux of hepatic artery blood from the liver, (2) an open state of the numerous arteriovenous connections in the gut, or (3) very modest oxygen consumption by the gut during absorption. Whether or not these speculations are correct or some other cause exists, the finding casts a reasonable doubt on estimates of the moiety of blood supplied to the liver by hepatic artery and portal vein where gauged by gases from portal vein blood (8). The very low levels of oxygen in systemic venous blood are puzzling although reduced oxygen content of the blood has been reported in cirrhotics (23).

Venous pressure. The dynamic state of the portal circulation, a low pressure system suspended between two capillary beds and thus indeed a veri- table rete mirabile, has been well hidden. Our only information in man has come from surgeons who have measured pressure directly at laparotomy, usually in subjects with portal hypertension. Observations on abdominal veins by Levy and Burch (5) give no indication that portal anastomotic veins were used and the technique of occlusion used by Davidson, Gibbons and Faloon (24), while indicating the pressure which may be reached, introduces an artifact if any appreciable quantity of blood flow is obstructed. Our observations were carried out the day after abdominal paracentesis, when there was relatively little distention, even though some ascitic fluid remained. The portal pressure of 22 and $19 \mathrm{~cm}$. of water in the two subjects was significantly higher than the systemic venous pressure (Table III). The Valsalva maneuver and hepatic jugular reflux test produced the expected changes.

Circulation time studies (Table II) suggest that blood from the anastomotic vein traversed a shorter distance or moved more rapidly than that from the arm.

\section{RESUMÉ}

The data on absorption and portal circulation gained from two subjects with portal anastomotic veins who were fed a mixture of test substances permit the following tentative statements:

1. Carbohydrate was absorbed rapidly from the upper part of the alimentary canal and the high level was sustained 90 minutes or more.

2. Thiamine, though it reached high levels in portal blood, did not rise significantly in systemic venous blood.

3. Ascorbic acid levels did not differ in portal and systemic blood during the rise following absorption.

4. Vitamin A was absorbed rapidly from the upper alimentary canal and systemic blood levels rose more slowly and not to the same degree.

5. The fasting level of lipids initially was lower in portal blood than in blood from the arm vein. In two instances there was an early fall followed by a sharp rise.

6. Amino acid rise in portal vein was delayed, variable and of small degree. Urea nitrogen was higher in systemic than portal blood during much of the absorption period, but the erratic behavior precludes analysis. 
TABLE $\mathrm{V}$

\begin{tabular}{|c|c|c|c|c|}
\hline Subject. . & M. W. & M. W. & M. W. & N. N. \\
\hline 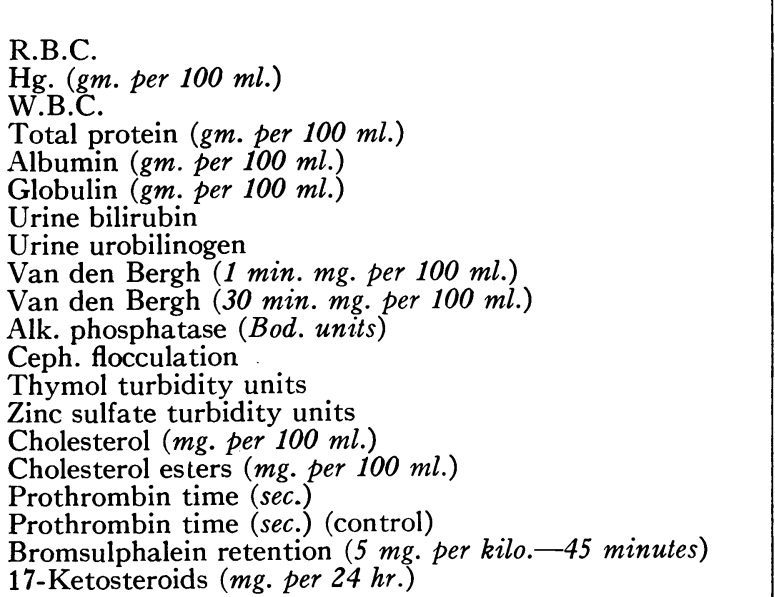 & $\begin{array}{c}12-11-48 \\
4.2 \\
13 \\
7,000 \\
5.4 \\
2.5 \\
2.9 \\
0 \\
4+ \\
3.3 \\
5.2 \\
4+ \\
22 \\
187 \\
83 \\
46 \\
36.3 \\
44 \% \\
-\end{array}$ & $\begin{array}{c}12-22-48 \\
4.0 \\
13 \\
6,300 \\
6.5 \\
3.0 \\
3.5 \\
0 \\
4+ \\
0.5 \\
2.7 \\
6.4 \\
3+ \\
26 \\
25 \\
233 \\
152 \\
- \\
- \\
- \\
-\end{array}$ & $\begin{array}{c}3-28-49 \\
4.9 \\
14 \\
9,100 \\
6.2 \\
2.9 \\
3.3 \\
0-3+ \\
4+ \\
- \\
1.8 \\
8.4 \\
2+ \\
27 \\
27 \\
324 \\
219 \\
44 \\
41.7 \\
29 \% \\
2.2\end{array}$ & $\begin{array}{r}6-28-49 \\
4.0 \\
11.9 \\
11,690 \\
6.4 \\
3.2 \\
3.1 \\
4+ \\
1+ \\
- \\
6.4 \\
17.2 \\
1+ \\
2.6 \\
11.0 \\
168 \\
75 \\
39 \\
29 \\
42 \% \\
1.4\end{array}$ \\
\hline
\end{tabular}

7. Oxygen content of portal vein blood was elevated, portal venous pressure was higher than systemic pressure and circulation time from anastomotic vein to tongue shorter than from arm to tongue.

8. These observations leave unanswered more questions than they illuminate. They emphasize a clinical finding first used by Sherlock and Walshe to solve some of the metabolic problems concealed in the hitherto inaccessible reaches of the portal blood system in man.

\section{APPENDIX}

\section{Case Reports}

$M . W$., a 43 year old railroad station agent, had three admissions to the Medical Service of the University Hospitals: 8 November-30 December, 1938; 21-30 March, 1949; and 30 September-5 October, 1949. His story on the first admission included a bout of "yellow jaundice" in 1932 and no recent but probably previous excessive use of alcohol. His illness began insidiously in March 1948 , with discomfort in both flanks, indigestion, sporadic nausea and vomiting. Within two months his belly became swollen, his appetite declined and food gave rise to a sensation of bloating. Though there was weakness, malaise and easy fatigability, his weight rose from 155 to 162 pounds. Hemorrhoids appeared during the month before admission. He had become aware of the advent of vascular spiders within six weeks of the onset of his illness. During the month before admission his ankles became swollen, especially in the evening. Prior to his iliness his diet was adequate. Nothing else of consequence was found in his past history or in the family history.
Examination disclosed a well-built, undernourished man without jaundice. He was alert, cooperative and in no acute distress. His skin had a slatey gray cast and was liberally sprinkled with vascular spiders though there was no palmar erythema or gynecomastia. Pectoral,

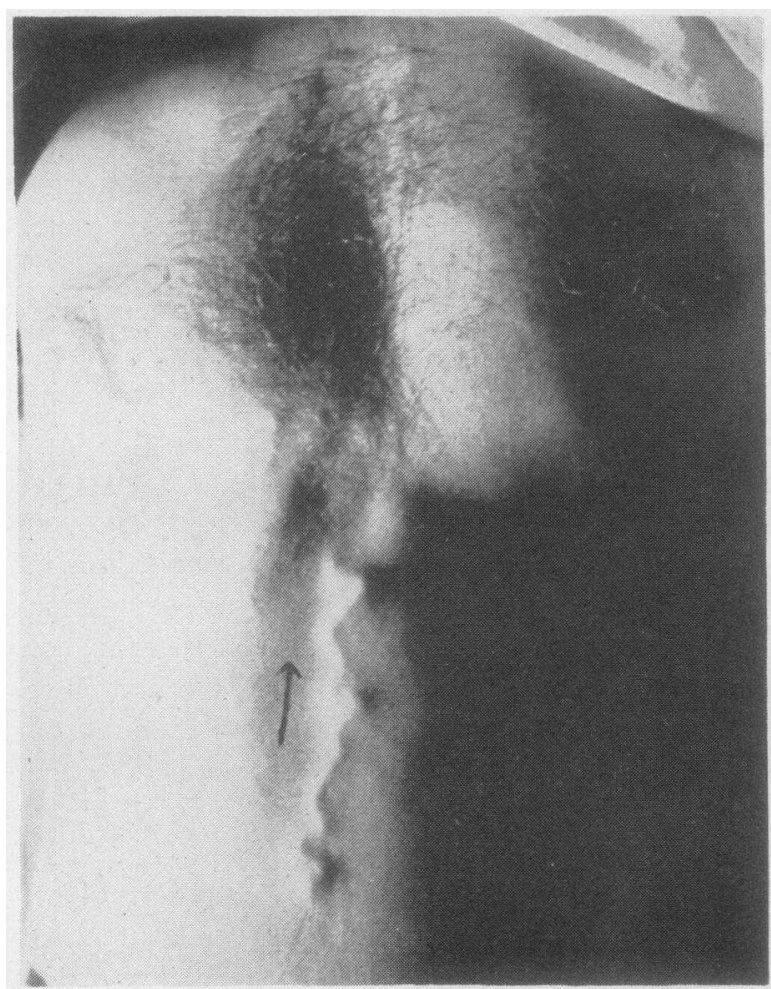

Fig. 9a. Photograph of Anterior Abdominal Wall Vein in Patient M. W. during a Valsalva Procedure Arrow marks direction of blood flow. 
pubic and axillary hair was ample. A few moist rales were heard at the right base posteriorly where impairment of the percussion note was found. The diaphragms were elevated and the abdomen was much distended. A fluid wave was found. There were a number of dilated veins coursing upward over the abdomen; and a very large one was found emerging in the midline to follow a tortuous course upward to the region of the xiphoid where it disappeared below the rib margin to the right. The Valsalva procedure caused it to stand out elegantly in relief (see Figure 9a). After paracentesis of 6 liters the spleen was felt, but not the liver. There were external hemorrhoids. Other features of the examination were not unusual.

Course: During the first admission he was kept in bed and given a diet high in protein and carbohydrate with supplemental vitamins. Salt was restricted and mercurial diuretics were used repeatedly. Five paracenteses, each yielding 5 to 6 liters, were done between 11 November and 28 December.
There was gradual though not very substantial improvement and he was sent home on the same regimen where he required abdominal paracentesis at about ten-day intervals.

Second admission: The physical signs had not changed appreciably. Laboratory data are included in Table V. Two paracenteses were done yielding 2 liters each and absorption studies were carried out. He was discharged on the same regimen as before.

Interval: During his stay at home he continued to become weaker but adhered to his diet and medication, needing paracentesis at weekly intervals. A few days before his final admission he suddenly became stuporous. Bright red blood was passed by rectum several times.

Final admission: It was suspected that some of the lethargy might have resulted from barbiturates which he had been given just prior to hospitalization. He became alert enough to eat after 4 liters of slightly turbid ascitic fluid were removed, but soon lapsed back into stupor. He was then sustained by intravenous glucose and

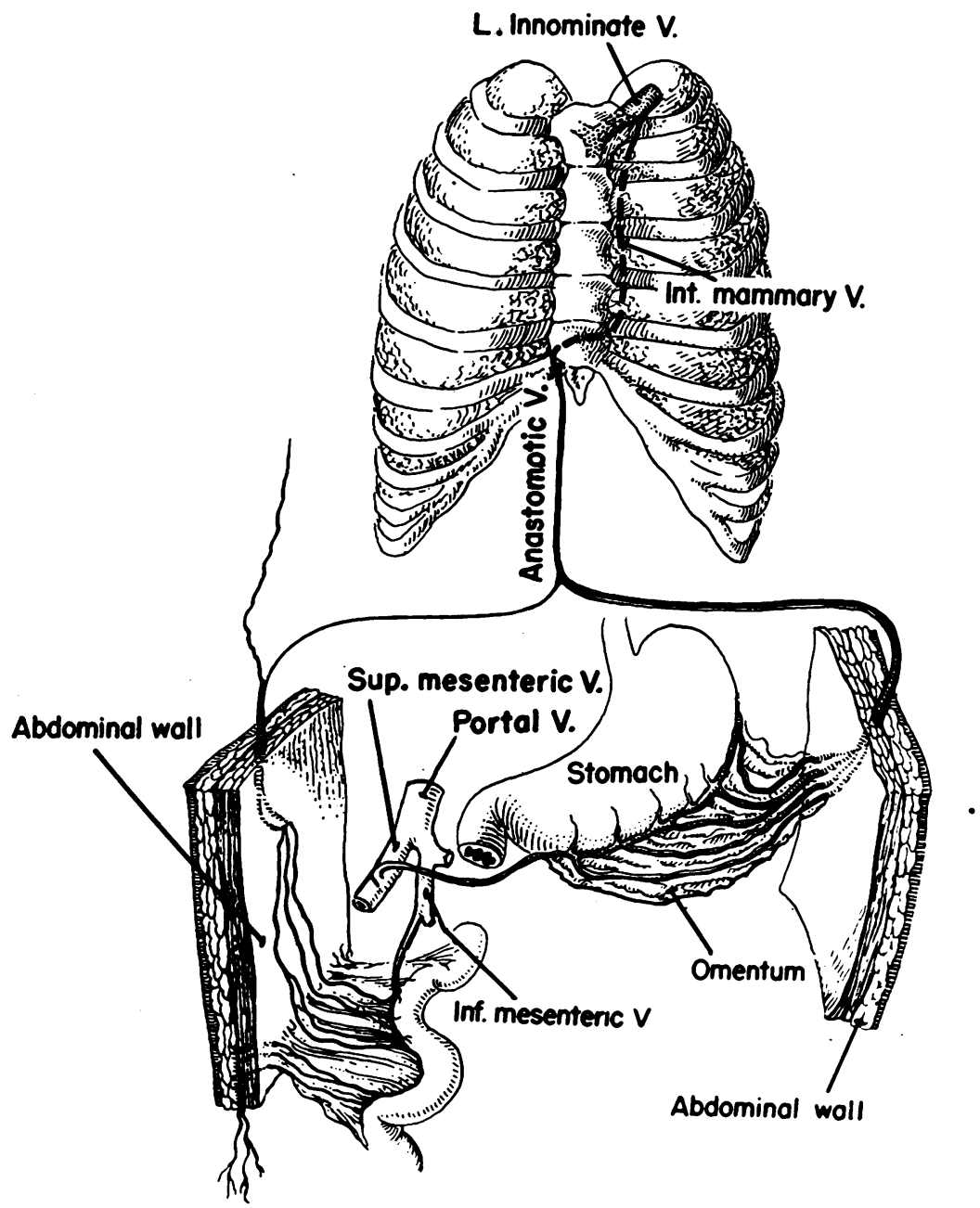

Fig. 9b. Diagram Illustrating Origin and Course of Abdominal Anastomotic Vein in Patient M. W. 
salt-free albumin. Clinical jaundice became apparent and bile appeared in the urine. He had vomited bloody fluid on two occasions shortly before he died.

Laboratory studies are summarized in Table V.

Autopsy: The significant findings were severe portal cirrhosis with ruptured esophageal varices and hemorrhage into the gastro-intestinal tract. A chronic congestive splenomegaly and abdominal ascites of approximately $1500 \mathrm{ml}$. of bile-stained fluid were present. There was great dilatation of the esophageal, gastric, paraumbilical and hemorrhoidal veins. The parietal peritoneal veins were distinctly dilated, particularly of both lateral peritoneal gutters and in the left upper abdomen where the greater omentum was adherent. The dilated omental veins originating from the stomach communicated with the lateral parietal veins in the left upper abdomen (Figures $9 \mathrm{a}, \mathrm{b}$ and $10 \mathrm{a}, \mathrm{b})$. Most of this latter plexus of veins formed a single vein, which ran ventrally and emerged superficially about 2 inches above the umbilicus. There it received a small tributary from the dilated plexus of veins in the right peritoneal gutter which in turn communicated with intestinal veins via the mesentary. After becoming superficial the abdominal vein coursed cephalad and pierced the deep tissues in the region of the xiphisternum slightly to the right. It then turned to the left and joined the left internal mammary vein on the posterior surface of the anterior chest wall. This in turn entered the left innominate vein (Figures 9 and 10 ).

$N$. N., a 51 year old German truck driver, was admitted to the Medical Service of the University Hospitals 27 June and discharged 23 August, 1949. There had been a brief visit to the Medical Out-Patient Clinic in October, 1938, when an anxiety state was suspected. At that time he was drinking beer occasionally. There was no evi-

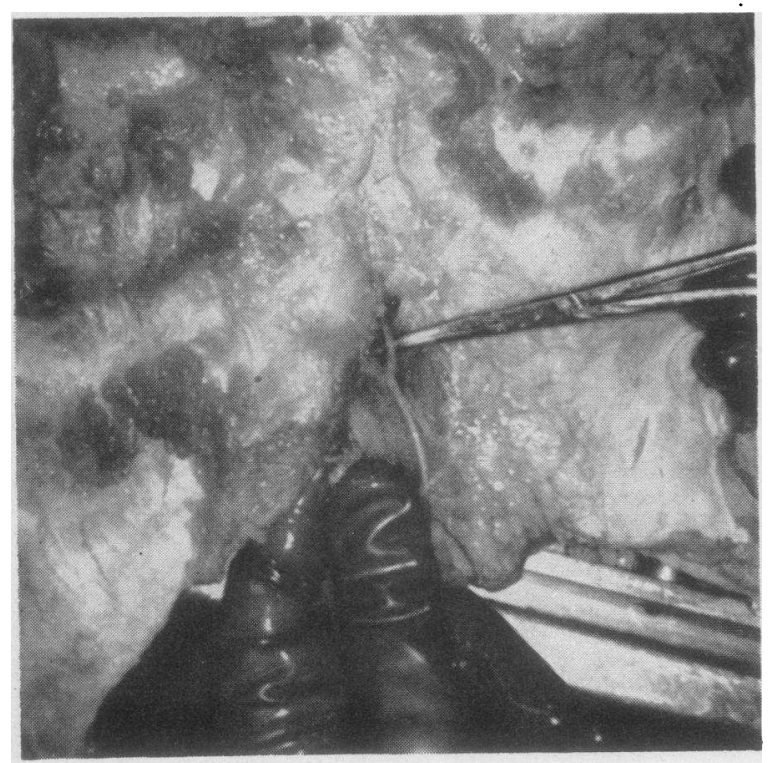

Fig. 10a. Photograph Showing Axastomotic Vein Piercing Anterior Surface of Chest Wall in Region of Xiphisternum

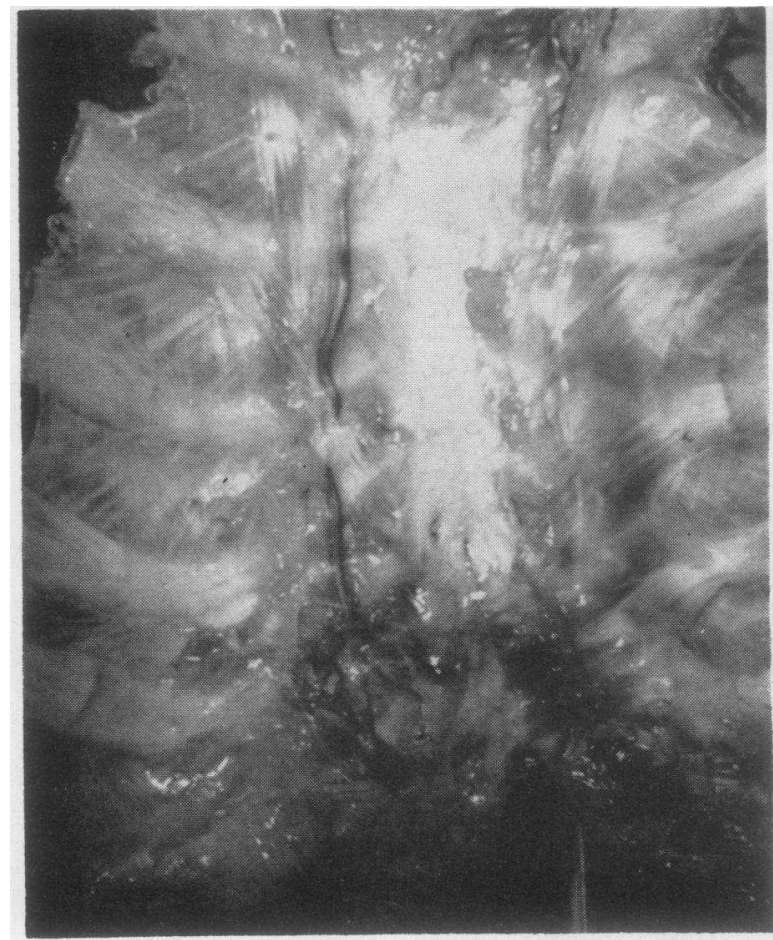

Fig. 10b. Photograph of Posterior Surface of Anterior Chest Wall Showing Left Internal Mammary Vein Which Has Just Been Jorned by the Anastomotic Vein Described in Figure 10a.

dence of liver disease. He reported a severe bout of malaria with coma two years previously.

During the year before admission insidiously beginning fatigue had progressed to a state of incapacity for the last three months. One month before entry abdominal discomfort, bloating and anorexia dominated the scene There was diarrhea. Chilly feelings and fever occurred repeatedly until a week before admission when he took quinine. The urine became dark three weeks before admission but he had not noticed jaundice or itching. His weight declined from 170 to 135 pounds in spite of increase in his girth which interfered with comfortable breathing.

Examination revealed an ill man, whose swollen belly contributed to orthopnea. The skin was not iaundiced but exposed areas were tanned. Vascular spiders were scattered over the chest, arms and shoulders. The sclerae were icteric. Retinal vessels showed moderate sclerosis. The left side of the chest was restricted in movement and the trachea deviated to the right. Signs of fluid were noted on the left. A harsh systolic murmur, transmitted into the neck, was heard in the second and third interspaces on the right; and $P_{2}$ was accentuated. Fluid distended the abdomen. The firm irregular edge of the liver was felt $5 \mathrm{~cm}$. below the rib margin on the right. The spleen was not felt. Pitting edema of the ankles was noted. Body and axillary hair were plentiful. A large anastomotic vein arising midway between umbilicus and 
xiphoid carried blood upwards. Large hemorrhoids were found.

Laboratory studies are summarized in Table V.

Treatment consisted of bedrest, high-protein, high-carbohydrate and low-salt diet supplemented with vitamins. Crude liver extract and mercuhydrin were given at frequent intervals. The left side of the chest was tapped on two occasions and $800 \mathrm{ml}$. of fluid removed each time. A number of abdominal paracenteses were performed with removal of 1-2 liters. Absorption and pressure studies were done on 15 August, 1949. The jaundice diminished and there was some clinical improvement, but he was still accumulating fluid at the time of discharge. He died at home on 1 September, 1949.

\section{REFERENCES}

1. Blakemore, A. H., The portacaval shunt in the surgical treatment of portal hypertension. Ann. Surg., 1948, 128, 825.

2. Linton, R. R., Portacaval shunts in the treatment of portal hypertension, with special reference to patients previously operated upon. New England J. Med., 1948, 238, 723.

3. Bradley, S. E., Ingelfinger, F. J., Bradley, G. P., and Curry, J. J., The estimation of hepatic blood flow in man. J. Clin. Invest., 1945, 24, 890.

4. Sherlock, S., and Walshe, V., The use of a portal anastomotic vein for absorption studies in man. Clin. Sc., 1946, 6, 113.

5. Levy, L. K., and Burch, G. E., Studies on venous pressure in hepatic cirrhosis. Ann. Int. Med., 1948, 29, 274.

6. Hitzig, W. M., Venous pressure curves in normal and abnormal circulatory states. I. Normal venous pressure curves and the negative "hepato jugular reflux phenomenon." J. Mt. Sinai Hosp., 1945, 12, 309.

7. Billings, F. T., Jr., and DePree, H. E., Diagnosis of portal vein obstruction; studies of intestinal absorption of glucose using abdominal collateral veins. Bull. J. Hopkins Hosp., 1949, 85, 183.

8. Myers, J. D., The hepatic blood flow in Laennec's cirrhosis with an estimate of the relative contributions from portal vein and hepatic artery. J. Clin. Invest., 1950, 29, 836.

9. Armstrong, E. L., Adams, W. L., Jr., Tragerman, L. J., and Townsend, E. W., The Cruveilhier-Baumgarten syndrome; review of the literature and report of two additional cases. Ann. Int. Med., 1942, $16,113$.
10. Dock, W., The clinical significance of some peculiarities of the circulation in the kidneys, liver, lungs, and heart. New England J. Med., 1947, 236, 773.

11. Gibson, R. B., Micro-determination of blood sugar. Proc. Soc. Exper. Biol. \& Med., 1930, 27, 480.

12. Corcoran, A. C., and Page, I. H., Application of diphenylamine in determination of levulose in biological media : determination of inulin; determination of levulose in small amounts of blood. J. Biol. Chem., 1939, 127, 601.

13. Sobel, A. E., and Werbin, H., Determination of vita$\min A$ in fish-liver oils with activated glycerol dichlorohydrin-comparison with spectrophotometric and antimony trichloride methods. Analyt. Chem., 1947, 19, 107.

14. Sobel, A. E., and Snow, S. D., Estimation of serum vitamin A with activated glycerol dichlorhydrin. J. Biol. Chem., 1947, 171, 617.

15. Gibson, R. B., and Lowe, R. C., Blood lipids; a gravimetric modification of the Morrissey method, used in the pathological chemistry laboratory. University Hospitals, University of Iowa Medical School.

16. Greenberg, L. D., and Rinehart, J. F., Methods for determination of thiamine in blood and tissues with observations on relative contents. Proc. Soc. Exper. Biol. \& Med., 1945, 59, 9.

17. Olinger, Z. M., Estimation of blood thiamin in human subjects. Modified in this laboratory-reported in Master's Thesis, SUI, 1949.

18. Stotz, E., Clinical method for the determination of ascorbic acid in blood plasma and urine. J. Lab. \& Clin. Med., 1941, 26, 1542.

19. Sahyum, M., Determination of amino nitrogen in blood and urine; rapid colorimetric method. J. Lab. \& Clin. Med., 1939, 24, 548. .

20. Von Mehring, Quoted by Sherlock and Walshe (4).

21. Jones, E., The demonstration of collateral venous circulation in the abdominal wall by means of infra-red photography. Am. J. M. Sc., 1935, 190, 478.

22. Cori, C. F., The fate of sugar in the animal body. III. The rate of glycogen formation in the liver of normal and insulinized rats during the absorption of glucose, fructose and galactose. J. Biol. Chem., 1926, 70, 577.

23. Ratnoff, O. D., and Patek, A. J., Jr., The natural history of Laennec's cirrhosis of the liver; analysis of 386 cases. Medicine, 1942, 21, 207.

24. Davidson, C. S., Gibbons, T. B., and Faloon, W. W., Systemic and portal venous pressures in cirrhosis of the liver. J. Lab. \& Clin. Med., 1950, 35, 181. 